\title{
Complex postglacial recolonization inferred from population genetic structure of mottled sculpin Cottus bairdii in tributaries of eastern Lake Michigan, U.S.A.
}

\author{
Authors: J. J. Homola, C. R. Ruetz III, S. L. Kohler, \\ and Ryan A. Thum
}

This is the peer reviewed version of the following article: (See citation, below.), which has been published in final form at https://dx.doi.org/10.1111/jfb.13101. This article may be used for noncommercial purposes in accordance with Wiley Terms and Conditions for Self-Archiving.

Homola, J J, C R III Ruetz, S L Kohler, and R A Thum. "Complex postglacial recolonization inferred from population genetic structure of mottled sculpin Cottus bairdii in tributaries of eastern Lake Michigan, U.S.A.." Journal of Fish Biology 89, no. 5 (November 2016): 2234-2250. DOI: 10.1111/jfb.13101.

Made available through Montana State University's $\underline{\text { ScholarWorks }}$ scholarworks.montana.edu 


\title{
Complex postglacial recolonization inferred from population genetic structure of mottled sculpin Cottus bairdii in tributaries of eastern Lake Michigan, U.S.A.
}

\author{
J. J. Homola*†, C. R. Ruetz III*, S. L. KohleR $\$$ And R. A. Thum§ \\ *Robert B. Annis Water Resources Institute, Grand Valley State University, 740 W. Shoreline \\ Drive, Muskegon, MI 49441, U.S.A., $\ddagger$ Department of Biological Sciences and Environmental \\ and Sustainability Studies Program, Western Michigan University, Kalamazoo, MI 49008, \\ U.S.A.and §Department of Plant Sciences \& Plant Pathology, Montana State University, \\ P. O. Box 173150, Bozeman, MT 59717, U.S.A.
}

(Received 8 July 2015, Accepted 27 June 2016)

\begin{abstract}
This study used analyses of the genetic structure of a non-game fish species, the mottled sculpin Cottus bairdii to hypothesize probable recolonization routes used by cottids and possibly other Laurentian Great Lakes fishes following glacial recession. Based on samples from 16 small streams in five major Lake Michigan, U.S.A., tributary basins, significant interpopulation differentiation was documented (overall $F_{\mathrm{ST}}=0 \cdot 235$ ). Differentiation was complex, however, with unexpectedly high genetic similarity among basins as well as occasionally strong differentiation within basins, despite relatively close geographic proximity of populations. Genetic dissimilarities were identified between eastern and western populations within river basins, with similarities existing between eastern and western populations across basins. Given such patterns, recolonization is hypothesized to have occurred on three occasions from more than one glacial refugium, with a secondary vicariant event resulting from reduction in the water level of ancestral Lake Michigan. By studying the phylogeography of a small, non-game fish species, this study provides insight into recolonization dynamics of the region that could be difficult to infer from game species that are often broadly dispersed by humans.
\end{abstract}

Key words: colonization; Laurentian Great Lakes; microsatellites; mtDNA; phylogeography; sedentary fish.

\section{INTRODUCTION}

Reconstruction of postglacial recolonization histories can provide a better understanding of not just ancient history, but important ecological and evolutionary processes shaping diversity in various taxa and regions. For example, pairing hypothesized species recolonization routes with geological histories can improve the understanding of the physical features capable of facilitating or impeding spread of different species, or genetic variation within species, across landscapes (Shafer et al., 2010). Also, this information can be informative for practical purposes such as predicting the response 
of populations to future climate oscillation as well as identifying cryptic intraspecific diversity (Hickerson et al., 2010; Marske et al., 2013).

The analysis of population genetic structure in light of the geographical locations of modern populations (i.e. phylogeography; Avise et al., 1987) provides a means to reconstruct colonization processes that were important in shaping postglacial patterns of biodiversity. Traditionally, colonization routes of fishes in areas affected by glaciation have been identified using the distribution of morphologically distinct species (Bailey \& Smith, 1981), but because the vicariant events that occurred during the late Pleistocene glaciations were generally too recent to allow recognizable morphological differentiation (Hewitt, 1996; Klicka \& Zink, 1997), and because different refugia often supported overlapping species pools (Bernatchez \& Wilson, 1998), patterns of interspecific diversity alone provide limited resolution to reconstruct complex colonization dynamics occurring at smaller regional scales. Intraspecific diversity, inferred from genetic data, can provide greater resolution over more modest temporal and spatial scales. Phylogeographic studies have been effective in determining clade structuring within species and subsequently relating such structure with geographic features to test regional colonization hypotheses (April \& Turgeon, 2006; Piller et al., 2008). By identifying contemporary population genetic structuring in freshwater fishes, researchers have formed hypotheses regarding historic and modern barriers to gene flow and species' dispersal capabilities by quantifying introgression among distinct clades (Ray et al., 2006; Faber et al., 2009).

North America's most recent glacial episode, the Wisconsin glaciation, reshaped the landscape and biota across the Great Lakes region. When the glacier's maximum extent occurred 23000-18000 years before present (B.P.; Dyke \& Prest, 1987), the Laurentian Great Lakes region was entirely covered by ice and the region's aquatic biota had retreated to refugia throughout the Mississippi and Ohio River basins and beyond (Murdoch \& Hebert, 1997; Stepien \& Faber, 1998). Glacial recession left the depressions that eventually became the modern Laurentian Great Lakes, but recolonization of tributary waterways occurred slowly over millennia as further retreat and isostatic rebound caused refugia to be reconnected. The well-documented postglacial patterns of geological recession in the region (Dyke \& Prest, 1987; Colman et al., 1994) provide a detailed resource for comparison with inferred phylogeographic patterns.

Several characteristics of the mottled sculpin Cottus bairdii Girard 1850 make it an excellent species for phylogeographic study. This small, benthic stream fish is typically sedentary over short ecological time scales (Petty \& Grossman, 2004; Breen et al., 2009), limiting dispersal of individuals across the landscape and in turn allowing population structure to form relatively quickly across small spatial scales (Lamphere \& Blum, 2012). Additionally, this non-game species is not known to have had its distribution strongly altered through anthropogenic introductions, which are common of many game species. Therefore, its current population structure is more likely representative of historic structure and processes. Because of these attributes, $C$. bairdii could serve as an indicator species for inferring ancient refugia and postglacial recolonization routes of other stream-dwelling fish species with overlapping distributions in the Great Lakes region. In fact, European Cottus spp. have been used for regional specific phylogeographic study for this exact purpose (Englbrecht et al., 2000; Kontula \& Väinölä, 2001; Vonlanthen et al., 2007). Cottus spp. can be difficult to differentiate morphologically (Yokoyama \& Goto, 2005; Young et al., 2013), however, and the ranges of 
multiple Cottus spp., including multiple C. bairdii subspecies (Robins, 1954; Hubbs et al., 2004), have been observed throughout the Great Lakes region, making genetic verification of these species particularly important.

The main objective of this study was to quantify interpopulation genetic structure of C. bairdii across five adjacent Lake Michigan, U.S.A., tributary basins to evaluate the influence of contemporary and historic landscape features on population connectivity. A landscape genetic approach (Manel et al., 2003) was applied to microsatellite genetic data to test the null hypothesis of panmixia by detecting discontinuities in genetic structure that could be attributable to past or present landscape features. Specifically, the alternative hypotheses that genetic divergence followed an isolation-by-distance pattern (Wright, 1943; Slatkin, 1993) within and among major river basins were evaluated. Two secondary objectives were to assess the timing of genetic divergence and verify species assignment through analysis of mitochondrial DNA (mtDNA) sequencing. Because microsatellite loci mutate rapidly, it is often useful to pair these data with analysis of relatively slowly mutating mtDNA for inferring the timing of divergence events (Brunner et al., 1998).

\section{MATERIALS AND METHODS}

\section{SAMPLE COLLECTION AND PROCESSING}

Cottus bairdii was collected from a $25-75 \mathrm{~m}$ reach in each of the 16 tributaries (wetted width: $1.9-10 \cdot 1 \mathrm{~m}$ ) distributed among five western Michigan river basins [Homola et al., 2014; Fig. 1(a), (b)]. Backpack electrofishing was used to collect 20-30 individuals from each stream (excluding juveniles). Twenty $C$. bairdii from each stream were then randomly chosen for genetic analyses.

DNA was extracted from fin clips or dorsal white muscle tissue samples using Qiagen DNeasy extraction kits (www.qiagen.com). All C. bairdii were genotyped at six microsatellite loci: Cba-14 (Fiumera et al., 2002), Cco-09 (Fujishin et al., 2009), Cgo-18ZIM, Cgo-310MEHU (Englbrecht et al., 1999), Cgo-1114PBBE and Cott-290 (Nolte et al., 2005). Detailed PCR conditions are available in Table SI (Supporting Information). A randomly selected subset of 10 individuals from each site were sequenced at the mtDNA cytochrome $c$ oxidase I gene (coI; Table SI, Supporting Information). Sequencing and microsatellite allele visualization was performed using an ABI Prism 3130xl automated genetic analyser (Applied Biosystems; www.appliedbiosystems.com). Microsatellite alleles were scored using GeneMapper 3.7 (Applied Biosystems) and coI sequences were trimmed and aligned using MEGA 6.0 (Tamura et al., 2013).

\section{QUALITY CONTROL, GENETIC DIVERSITY AND SPECIES VERIFICATION}

The assumption that data were drawn from effectively neutral, independently segregating loci in randomly mating, diploid populations was assessed and genetic diversity was quantified for each site. Using 1000 data randomizations in Microchecker 2.2.1 (van Oosterhout et al., 2004), data were inspected for evidence of null alleles, stuttering or allelic dropout. Further examination using factor loadings of a discriminant analysis of principal components (DAPC; Jombart et al., 2010) was conducted using the adegenet package (Jombart, 2008) in R 2.15.2 (www.r-project.org). Conformation to Hardy-Weinberg equilibrium (HWE) assumptions and instances of significant linkage disequilibrium (LD) were evaluated using Arlequin (Excoffier $\&$ Lischer, 2010). A sequential Bonferroni-corrected critical $\alpha$-level (Rice, 1989) was used to assess statistical significance. Mean number of alleles $\left(N_{\mathrm{A}}\right)$, allelic richness using rarefaction to correct for differing sample sizes $(A)$ and number of private alleles $\left(N_{\mathrm{PA}}\right)$ were estimated for 


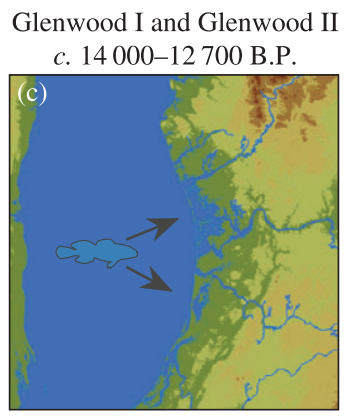

Algonquin

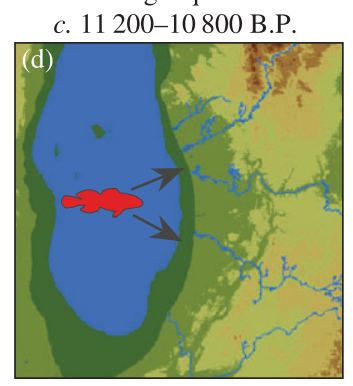

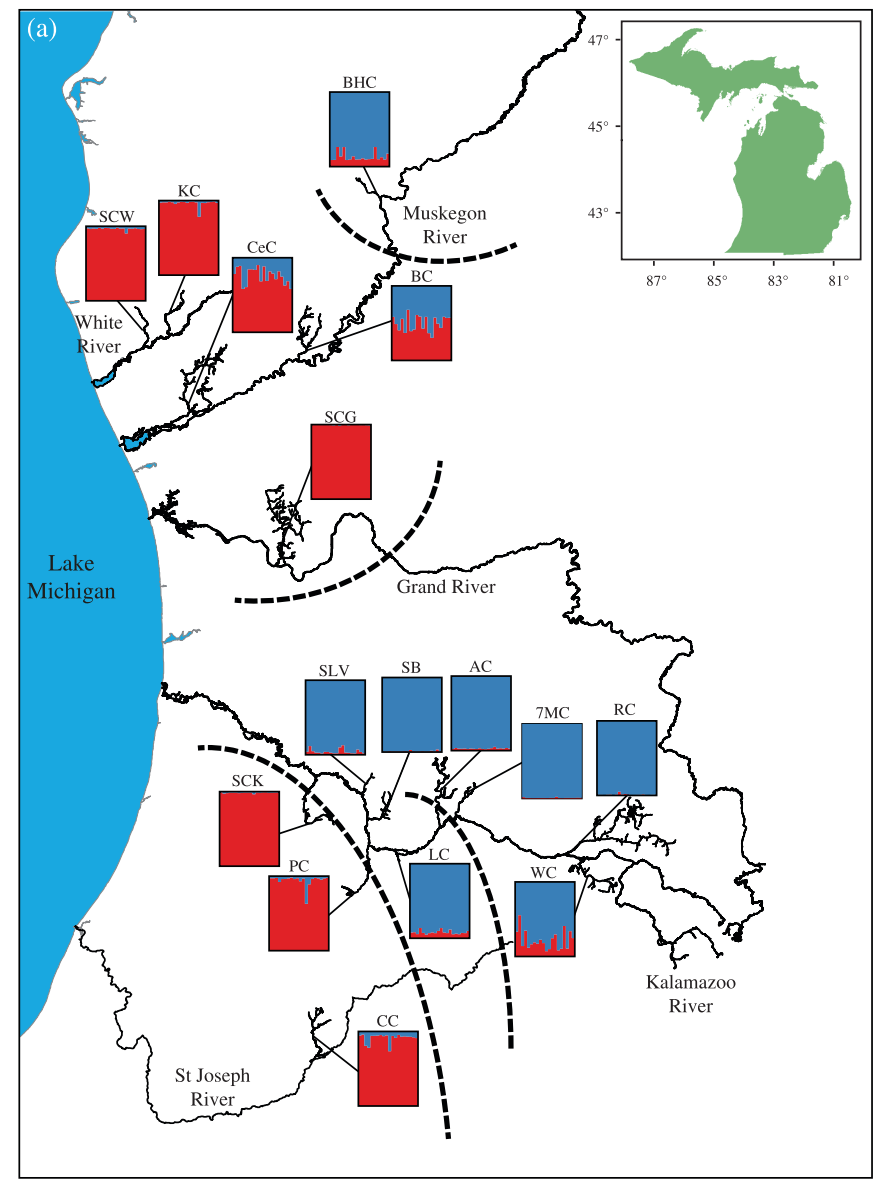

FIG. 1. Map of sampling sites (codes correspond with Table II) with results of (a, b) STRUCTURE (blue, red, purple and green plots) and BARRIER (----) analyses for six Cottus bairdii microsatellite loci sampled from 16 streams in western Michigan, U.S.A. The hypothesized population genetic structure is depicted as a (a) two-cluster ( $\square$, eastern; $\square$, western) and (b) four-cluster ( $\square$, initial colonization ; $\square$, second colonization; $\square$, northern river basins; $\square$, southern river basins) scenarios. Progression of Lake Michigan water levels throughout three de-glaciation stages [(c, e) Glenwood I and Glenwood II, 14 000-12 700 B.P.; (d, f) Algonquin, $11200-10800$ B.P.; and (g) Chippewa low, 10300 B.P.] with hypothesized recolonization scenarios [fish colours in panels (c)-(g) correspond to STRUCTURE diagram colours (blue, red, purple and green) in panels (a) and (b)] and water level illustrations approximated from Colman et al. (1994)].

each site using FSTAT 2.9.3.2 (Goudet, 2001). Observed heterozygosity $\left(H_{\mathrm{O}}\right)$, expected heterozygosity $\left(H_{\mathrm{E}}\right)$ and Wright's inbreeding coefficient $\left(F_{\mathrm{IS}}\right)$ were estimated for each site using GENEPOP 4 (Rousset, 2008).

Species verification was conducted by comparing haplotypes from sampled individuals with haplotypes from Cottus cognatus Richardson 1837 and Cottus ricei (Nelson 1876), which also occur in the Great Lakes region (Hubbs et al., 2004), as well as Cottus aleuticus Gilbert 1896 and Cottus asper Richardson 1837 as taxonomically similar outgroups. Haplotypes from voucher specimen were those previously described by Hubert et al. (2008). Relationships among haplotypes were assessed using a maximum likelihood phylogenetic tree constructed using MEGA. 
Glenwood I and Glenwood II c. $14000-12700$ B.P.

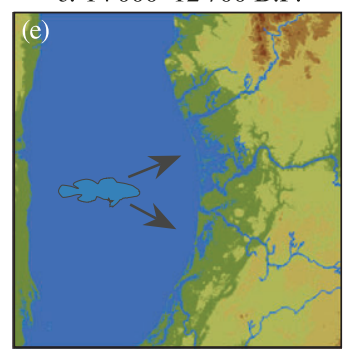

Algonquin c. $11200-10800$ B.P.

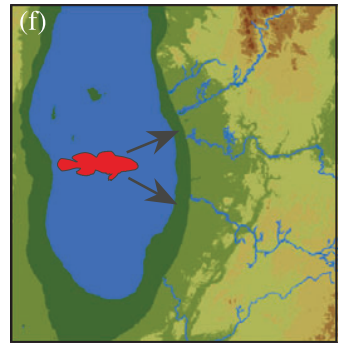

Chippea low c. 10300 B.P.

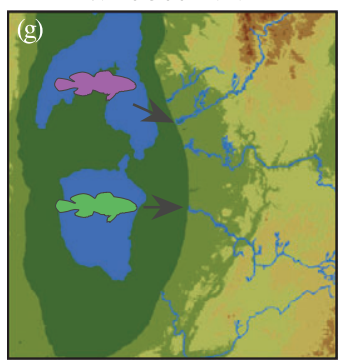

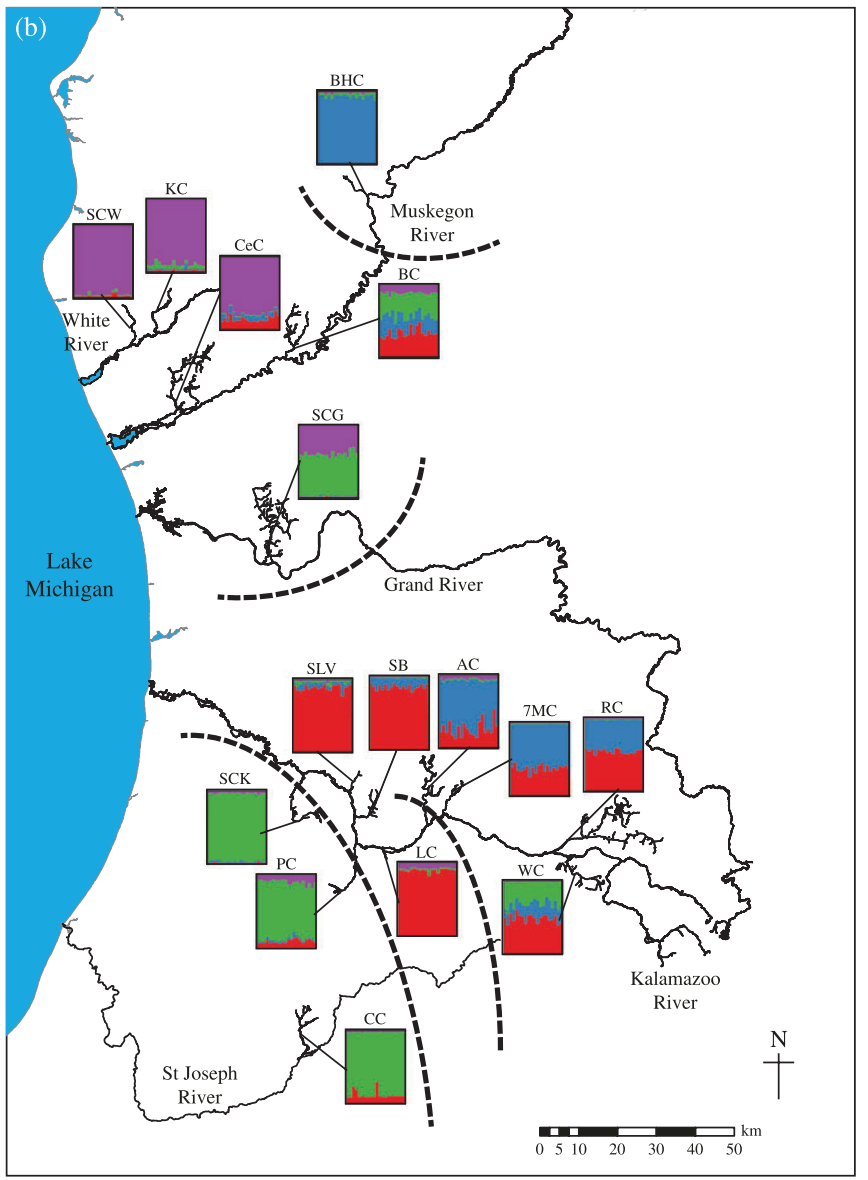

FIG. 1. Continued.

\section{POPULATION GENETIC STRUCTURE}

Population genetic structure based on microsatellite data was evaluated using several techniques. First, significance of interpopulation variances in allele frequency $\left(F_{\mathrm{ST}}\right)$ was quantified using a Fisher's exact test conducted in GENEPOP. Next, population pair-wise Cavalli-Sforza chord distances $\left(D_{\mathrm{C}}\right.$; Cavalli-Sforza \& Edwards, 1967) were estimated using microsatellite analyser (Dieringer \& Schlötterer, 2003). Third, the hypothesis of strong isolation by distance (IBD) was tested by comparing $D_{\mathrm{C}}$ and linearized $F_{\mathrm{ST}}\left[F_{\mathrm{ST}}\left(1-F_{\mathrm{ST}}\right)^{-1}\right.$; Slatkin, 1993] with geographic distances using Mantel tests implemented in the R-package vegan (Oksanen et al., 2012). Two different measures of geographic distance were used. The first distance matrix was based on straight-line (i.e. Euclidian) distances and the second used waterborne distances between each population pair. Waterborne distances, which are based on hydrologic connectivity, were used as a measure of contemporary population connectivity via existing stream channels. All geographic distance measurements were performed using ArcGIS (ESRI, 2011). Fourth, a Bayesian clustering algorithm was implemented using STRUCTURE 2.3 (Pritchard et al., 2000; Falush et al., 2003, 2007; Hubisz et al., 2009) to evaluate and visualize the population genetic structure present among the study populations. This technique is useful for determining the number of genetically distinct clusters $(K)$ as well as estimating the amount of admixture that occurs 
within individuals. STRUCTURE analyses were performed using a correlated allele frequency model both with and without sampling location as a prior (LOCPRIOR option). A Markov chain Monte-Carlo (MCMC) simulation was run for 250000 steps (with 50000 discarded as burn-in for $K=1-17$ ) with 10 independent runs conducted for each value of $K$. The number of clusters was determined using the $\Delta K$ method (Evanno et al., 2005) as estimated in the web-based programme STRUCTURE HARVESTER (Earl \& vonHoldt, 2012). STRUCTURE results were orientated graphically using CLUMPP (Jakobsson \& Rosenberg, 2007) and DISTRUCT (Rosenberg, 2004). In addition to the Bayesian clustering analysis, a second method was used to identify discontinuities between genetic and geographic distances. Significant barriers to gene flow among the study populations were evaluated using Monmonier's (1973) maximum difference algorithm as implemented in the programme BARRIER 2.2 (Manni et al., 2004). This approach maps genetic differentiation (pair-wise $\theta_{\mathrm{ST}}$; Weir \& Cockerham, 1984) between adjacent sampling points that are projected using geographic co-ordinates (i.e. latitude and longitude). Spatial organization of populations was modelled using Delaunay triangulation with edges associated to genetic differentiation measures and subsequent Voronoi tessellation to establish potential interpopulation barriers (Manni et al., 2004). Support for each identified barrier was evaluated using 1000 bootstrapped distance matrices that were simulated using microsatellite analyser (Dieringer \& Schlötterer, 2003). Finally, a neighbour-joining tree based on $D_{\mathrm{C}}$ was assembled using PHYLIP 3.69 (Felsenstein, 2005). Support for branch configuration was determined using 500 bootstrapped pseudoreplicates.

\section{RESULTS}

\section{QUALITY CONTROL, GENETIC DIVERSITY AND SPECIES VERIFICATION}

Amplification was successful at 1894 of 1920 potential individual locus combinations $(98.6 \%)$ and genotypes were obtained for every individual for at least five loci except for one individual in Buckhorn Creek that was subsequently excluded from analyses. Evidence of null alleles was found for locus $\mathrm{Cgo}-310 \mathrm{MEHU}$ in the Bigelow Creek and Cedar Creek populations (estimated frequency: 0.15 for each population). DAPC indicated that no alleles of $\mathrm{Cgo}-310 \mathrm{MEHU}$ were disproportionately influencing analyses; moreover, statistical analyses performed both with and without the locus were qualitatively similar. Therefore, locus $\mathrm{CgO}-310 \mathrm{MEHU}$ was retained for analyses. One population-locus pairing was found to significantly deviate from HWE assumptions (Cgo-1114PBBE for Silver Creek) and no evidence of linkage disequilibrium was detected.

All amplified microsatellite loci were polymorphic and had allelic richness values that ranged from 1.66 ( $\mathrm{Cba}-14$ ) to 7.89 ( $\mathrm{CcO}-09$; Table I). Microsatellite genetic diversity varied considerably among streams and patterns varied among the six measures of genetic diversity (Table II). The mean number of alleles was lowest in Lee Creek (2.00) and highest in Spring Brook (3.50). Allelic richness was lowest in Lee Creek (1.98) and highest in Spring Brook (3·36). Observed heterozygosity was lowest in Buckhorn Creek $(0 \cdot 14)$ and highest in Seven Mile Creek $(0 \cdot 50)$. Wright's inbreeding coefficient was lowest in Knutson Creek (-0.21) and highest in Silver Creek (0.45).

A $637 \mathrm{bp}$ fragment of the mtDNA coI gene was successfully amplified for all sequenced individuals. coI sequences contained eight unique haplotypes with 134 of 160 sequenced individuals conforming to a predominate haplotype [Fig. 2(a)]. No haplotype differed from the predominate haplotype by more than two single nucleotide polymorphisms $(0.3 \%$ of sequence read). Additionally, all haplotypes grouped closely 
TABLE I. Measures of locus-specific genetic diversity for 16 Cottus bairdii populations genotyped at six microsatellite loci including mean number of alleles $\left(N_{\mathrm{A}}\right)$, allelic richness $(A)$, observed heterozygosity $\left(H_{\mathrm{O}}\right)$, expected heterozygosity $\left(H_{\mathrm{E}}\right)$ and Wright's inbreeding coefficient $\left(F_{\text {IS }}\right)$

\begin{tabular}{|c|c|c|c|c|c|}
\hline Locus & $N_{\mathrm{A}}$ & $A$ & $H_{\mathrm{O}}$ & $H_{\mathrm{E}}$ & $F_{\text {IS }}$ \\
\hline Cba-14 & 3 & 1.66 & $0 \cdot 05$ & 0.05 & 0.06 \\
\hline Cco-09 & 12 & $7 \cdot 89$ & 0.66 & 0.68 & 0.04 \\
\hline Cgo-18ZIM & 7 & 4.92 & 0.47 & $0 \cdot 46$ & $0 \cdot 00$ \\
\hline Cgo-310MEHU & 4 & 1.72 & 0.03 & $0 \cdot 06$ & 0.56 \\
\hline Cgo-1114PBBE & 9 & $4 \cdot 37$ & $0 \cdot 34$ & $0 \cdot 36$ & 0.07 \\
\hline Cott-290 & 11 & $3 \cdot 85$ & $0 \cdot 38$ & $0 \cdot 35$ & -0.06 \\
\hline
\end{tabular}

with haplotypes of $C$. bairdii voucher specimen, indicating that no other morphologically similar species were inadvertently included in analyses (Fig. S1, Supporting Information).

\section{POPULATION GENETIC STRUCTURE}

Microsatellite analyses indicated that strong interpopulation genetic differentiation existed among populations. A range of $F_{\mathrm{ST}}$ values was detected from a low of 0.039 (Silver Creek-Lee Creek) to a high of 0.548 (Buckhorn Creek-Lee Creek; Table III). Significantly different $F_{\mathrm{ST}}$ values were observed for all pair-wise combinations and the

TABLE II. Measures of genetic diversity for 16 Michigan Cottus bairdii populations including mean number of alleles $\left(N_{\mathrm{A}}\right)$, allelic richness $(A)$, observed heterozygosity $\left(H_{\mathrm{O}}\right)$, expected heterozygosity $\left(H_{\mathrm{E}}\right)$, Wright's inbreeding coefficient $\left(F_{\mathrm{IS}}\right)$ and number of private alleles $\left(N_{\mathrm{PA}}\right)$ estimated using six microsatellite loci

\begin{tabular}{|c|c|c|c|c|c|c|c|c|}
\hline River basin & Stream & Abbreviation & $N_{\mathrm{A}}$ & $A$ & $H_{\mathrm{O}}$ & $H_{\mathrm{E}}$ & $F_{\text {IS }}$ & $N_{\text {PA }}$ \\
\hline Grand & Sand Creek & SCG & $2 \cdot 67$ & $2 \cdot 62$ & $0 \cdot 37$ & $0 \cdot 39$ & $0 \cdot 05$ & 2 \\
\hline Kalamazoo & Augusta Creek & $\mathrm{AC}$ & $2 \cdot 50$ & $2 \cdot 41$ & $0 \cdot 25$ & $0 \cdot 27$ & 0.07 & 0 \\
\hline Kalamazoo & Lee Creek & $\mathrm{LC}$ & $2 \cdot 00$ & 1.98 & $0 \cdot 34$ & $0 \cdot 29$ & $-0 \cdot 18$ & 0 \\
\hline Kalamazoo & Portage Creek & $\mathrm{PC}$ & $2 \cdot 83$ & $2 \cdot 65$ & $0 \cdot 30$ & $0 \cdot 28$ & $-0 \cdot 07$ & 2 \\
\hline Kalamazoo & Rice Creek & $\mathrm{RC}$ & $2 \cdot 67$ & $2 \cdot 53$ & $0 \cdot 35$ & $0 \cdot 35$ & $0 \cdot 00$ & 2 \\
\hline Kalamazoo & Sand Creek & SCK & $3 \cdot 00$ & $2 \cdot 83$ & $0 \cdot 30$ & $0 \cdot 30$ & $0 \cdot 00$ & 1 \\
\hline Kalamazoo & Sevenmile Creek & $7 \mathrm{MC}$ & $3 \cdot 00$ & $2 \cdot 91$ & 0.50 & $0 \cdot 50$ & $-0 \cdot 01$ & 0 \\
\hline Kalamazoo & Silver Creek & SLV & $3 \cdot 00$ & $2 \cdot 91$ & $0 \cdot 19$ & $0 \cdot 34$ & 0.45 & 0 \\
\hline Kalamazoo & Spring Brook & SB & $3 \cdot 50$ & $3 \cdot 36$ & $0 \cdot 42$ & $0 \cdot 40$ & $-0 \cdot 04$ & 2 \\
\hline Kalamazoo & Wilder Creek & WC & $3 \cdot 16$ & $3 \cdot 04$ & $0 \cdot 40$ & 0.45 & $0 \cdot 12$ & 1 \\
\hline Muskegon & Bigelow Creek & $\mathrm{BC}$ & $3 \cdot 33$ & $3 \cdot 26$ & $0 \cdot 34$ & $0 \cdot 41$ & $0 \cdot 18$ & 0 \\
\hline Muskegon & Buckhorn Creek & $\mathrm{BHC}$ & $2 \cdot 33$ & $2 \cdot 24$ & $0 \cdot 14$ & $0 \cdot 15$ & 0.00 & 0 \\
\hline Muskegon & Cedar Creek & $\mathrm{CeC}$ & $2 \cdot 83$ & $2 \cdot 76$ & $0 \cdot 26$ & $0 \cdot 30$ & $0 \cdot 15$ & 0 \\
\hline St Joseph & Curtis Creek & $\mathrm{CC}$ & $3 \cdot 33$ & $3 \cdot 21$ & $0 \cdot 32$ & $0 \cdot 32$ & 0.01 & 1 \\
\hline White & Knutson Creek & $\mathrm{KC}$ & $2 \cdot 67$ & 2.50 & $0 \cdot 36$ & $0 \cdot 30$ & $0 \cdot 21$ & 1 \\
\hline White & Sand Creek & SCW & $2 \cdot 50$ & $2 \cdot 29$ & $0 \cdot 29$ & $0 \cdot 28$ & -0.05 & 1 \\
\hline
\end{tabular}




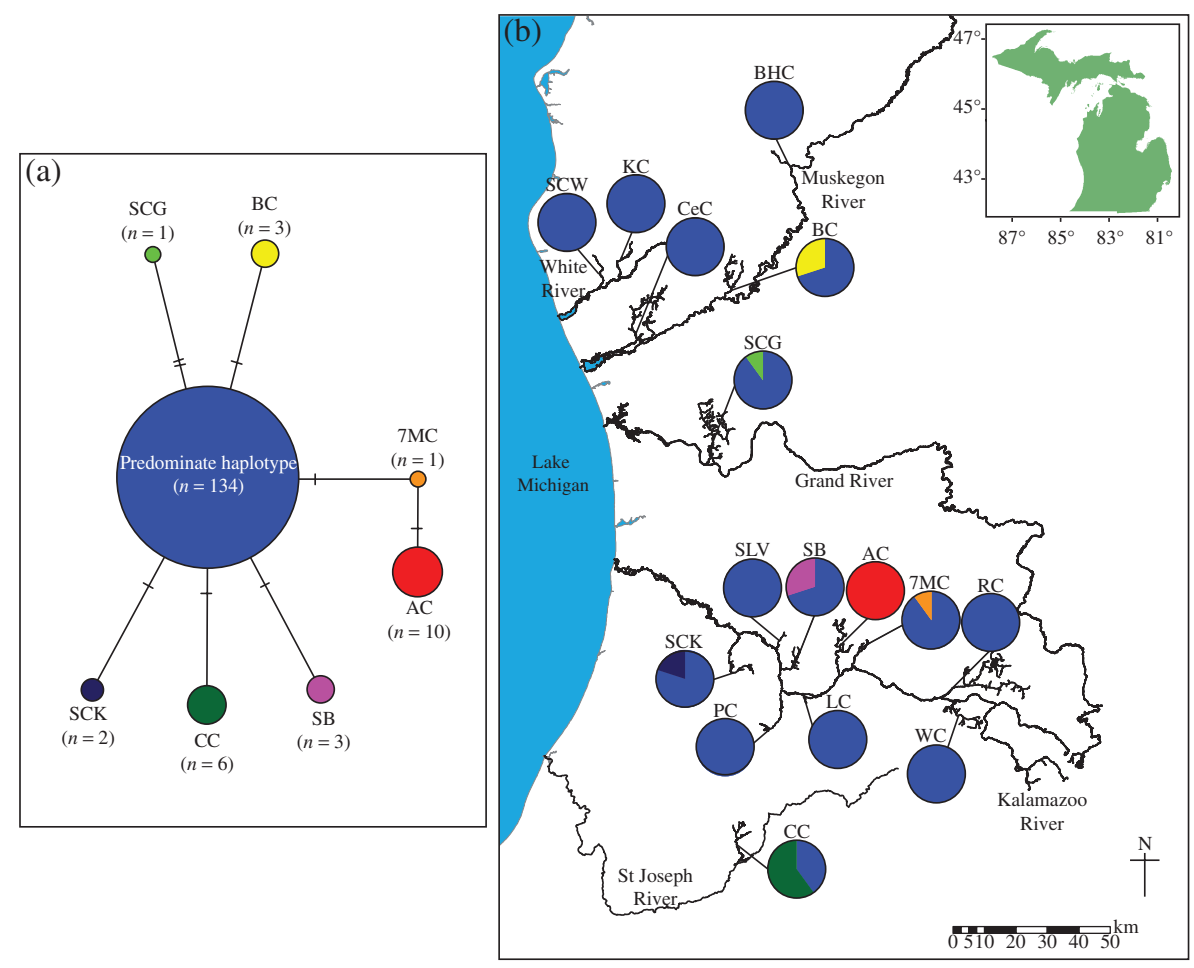

FIG. 2. Variability in mtDNA cytochrome oxidase I (col) sequences for 10 Cottus bairdii sampled from each of 16 streams (codes correspond with Table II) in western Michigan, U.S.A., displayed as (a) a haplotype network and (b) proportions of distinct haplotypes occurring at each sampling site. Colours correspond between panels (a) and (b).

overall $F_{\mathrm{ST}}$ was $0 \cdot 235$. Genetic-chord distances ranged from a low of $0 \cdot 160$ between Silver Creek and Lee Creek to a high of 0.471 between Seven Mile Creek and Sand Creek (White River basin) with an overall average distance of $0 \cdot 327$. There was statistical evidence for IBD using $D_{\mathrm{C}}$ and $F_{\mathrm{ST}}$ values with both Euclidean and waterborne distances $(P<0.05)$; however, the IBD model explained a small percentage of the variation in the data (Mantel's $r$-range: 0.07-0.14; Fig. S2, Supporting Information), suggesting that populations may be experiencing genetic drift independently of one another, thereby supporting a high degree of isolation.

Bayesian clustering analyses indicated considerable support for both $K=2$ and $K=4$ scenarios. A two-cluster scenario was most supported for analyses without the LOCPRIOR function [Fig. S3(a), Supplementary Information], whereas four unique genetic clusters received the highest support when using the LOCPRIOR function [Fig. S3(b), Supplementary Information]. STRUCTURE plots for both $K=2$ and $K=4$ with and without LOCPRIOR are available in Fig. S4 (Supplementary Information). Results for both $K=2$ and $K=4$ are described below, although the general patterns were similar for each scenario.

When considering a two-cluster scenario [Fig. 1(a), (c), (d)], an eastern cluster [blue in Fig. 1(a), (c)] and a western cluster [red in Fig. 1(a), (d)] were evident. A gradation among the eastern and western clusters was seen in the Muskegon River basin, but was 


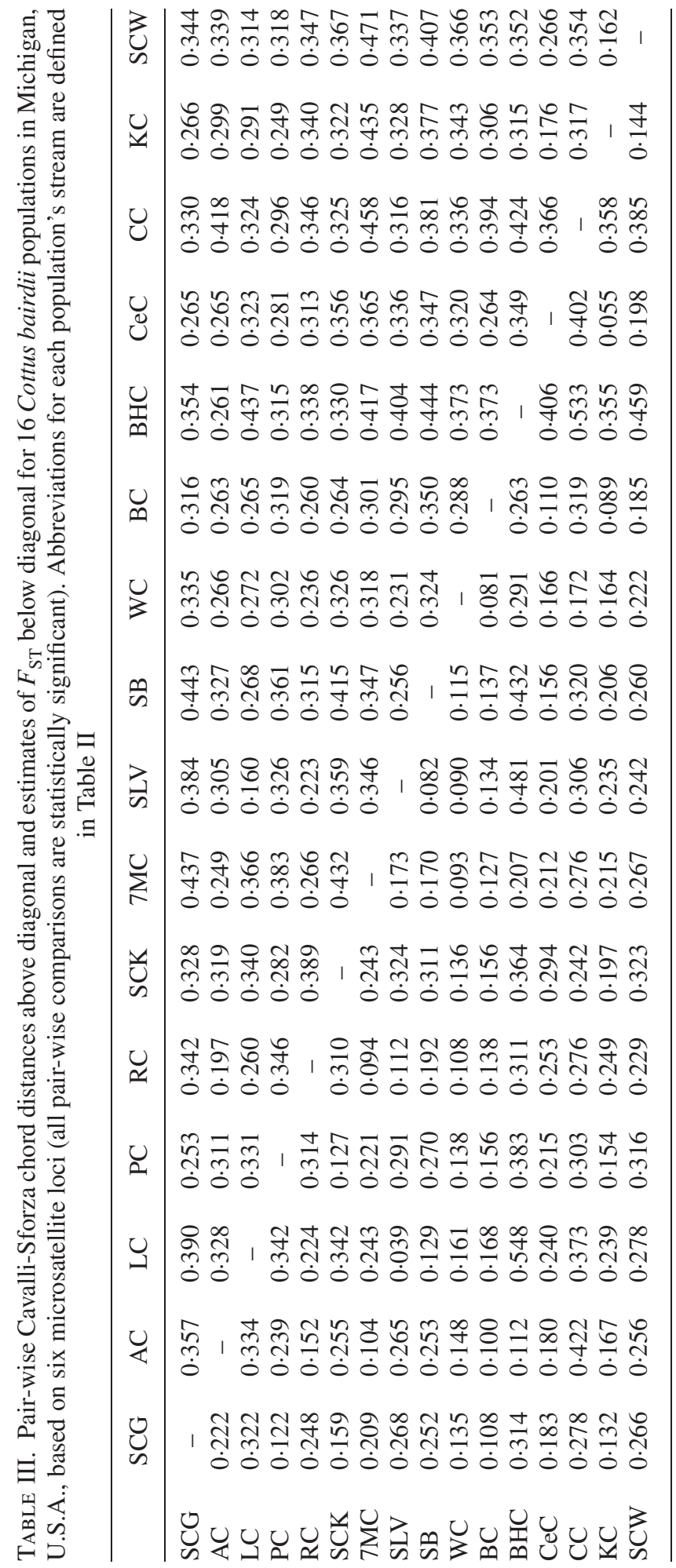


notably absent from the Kalamazoo River basin, which contained a clear separation from the eastern and western sides of the basin.

While eastern and western clusters were also detected in the four cluster scenario [Fig. 1(b), (e)-(g)], northern and southern divisions also emerged. One cluster [blue in Fig. 1(b), (e)] was strongly represented in both the upper Muskegon River basin (Buckhorn Creek) and throughout the eastern Kalamazoo River basin, making it clearly the most geographically dispersed cluster, yet it was consistently present in the easternmost study streams. A second cluster [red in Fig. 1(b), (f)] was most apparent in the central Kalamazoo River basin, with the third cluster [green in Fig. 1(b), (g)] being most evidently centralized in the western Kalamazoo River basin. The fourth cluster [purple in Fig. 1(b), (g)] occurred in tributaries of the White River and in the westernmost portion of the nearby Muskegon River basin. Individuals collected from the single location analysed from the Grand River basin (Sand Creek) showed notably strong evidence for admixture between the clusters located in the westernmost portions of rivers to the north and south.

Several instances where genetic distance was notably greater than expected given geographic proximity were identified. Specifically, Monmonier's maximum difference algorithm identified 10 interpopulation divisions with greater than $80 \%$ bootstrap support for containing barriers to gene flow [Fig. 1(a), (b)]. In most cases, these divisions occurred within major river basins rather than coinciding with contemporary catchments. This was evident between Buckhorn and Bigelow Creeks in the Muskegon River basin as well as two inferred barriers that isolate the three central streams in the Kalamazoo River basin (Silver Creek, Spring Brook and Lee Creek) from populations to their east and west. More importantly, the inferred barriers were not as well supported in the two-cluster scenario [Fig. 1(a)]. For instance, although the barrier separating Sand Creek (Kalamazoo River basin), Portage Creek and Curtis Creek from the remaining Kalamazoo River basin streams was clearly supported, the two-cluster scenario did not corroborate with the barriers inferred between Lee Creek and Augusta Creek in the Kalamazoo River basin. Similarly, the barrier between Buckhorn Creek and Bigelow Creek in the Muskegon River basin was not well supported with the two-cluster scenario, suggesting that important patterns may be omitted under a two-cluster scenario.

The phylogenetic tree mostly grouped populations based on geographic proximity (Fig. S5, Supplementary Information) rather than contemporary watersheds and generally supported the above analyses. Populations located in the western Kalamazoo River basin were positioned adjacent to those in the St Joseph River and Grand River basins. Notably, the separation of Sand Creek (White River basin), Knutson Creek and Cedar Creek from the western Kalamazoo River and St Joseph River populations provided further support for the four-cluster scenario [Fig. 1(b)]. Individuals sampled from Kalamazoo River tributaries were generally grouped with nearby locations. For instance, the four streams comprising the eastern portion of the basin grouped together (Rice Creek, Wilder Creek, Seven Mile Creek and Augusta Creek). An exception to structuring being based on geographic proximity was the placement of Buckhorn Creek (located in the upper Muskegon River basin) with individuals sampled in tributaries of the eastern Kalamazoo River. This result, however, coincided with both the two and four-cluster scenarios [Fig. 1(a), (b)] that indicated a high degree of similarity exists between individuals sampled at those sites.

Analysis of coI gene sequences did not identify clear genetic structure, as no haplotypes were shared across populations besides the predominate haplotype [Fig. 2(a)]. 
No apparent similarities exist when comparing population-wise variation in the coI gene with the microsatellite variation described above [Fig. 2(b)].

\section{DISCUSSION}

The interpopulation genetic structure for $C$. bairdii in the eastern Lake Michigan catchment failed to support the hypothesis that populations occurring within tributaries of the same major river basin have comparatively less interpopulation differentiation than populations from different river basins. Additionally, observed genetic structure does not appear to be influenced by other contemporary factors. For instance, examination of similarities among several environmental variables and resident fish assemblages at each sampling site for a concurrent study did not appear to coincide with genetic clustering identified by STRUCTURE analyses (Homola et al., 2014; Table SII, Supporting Information), reducing the likelihood that interpopulation structure could be a consequence of parallel evolution caused by similar selection pressures. Although dams often restrict fish movement (Pringle et al., 2000), the general pattern of genetic structure in this study does not appear to be strongly influenced by the location of dams in the connecting waterways (Fig. S6, Supporting Information). Instead, interpopulation structure appeared to exist on a generally east-west gradient, even for populations in different river basins. Therefore, the identified genetic structure probably provides novel insight into postglacial recolonization processes and timing.

Because the microsatellite interpopulation genetic structure does not appear to be reflective of separation caused primarily by the contemporary landscape, it is probably more representative of historic colonization processes. Specifically, the genetic structure documented here along with knowledge of historic geological and glacial processes are consistent with a hypothesis of a three-stage colonization scenario [Fig. 1(e)-(g)] to best explain the genetic structure of $C$. bairdii in the Lake Michigan basin study streams.

The results of this study support a first colonization event for C. bairdii in present-day western Michigan occurred following recolonization of Lake Chicago (ancestral Lake Michigan) from southern glacial refugia. An initial colonization event is supported by the similarities between inland populations across the analysed sites. These similarities between inland sites are present in both the two-cluster scenario [Fig. 1(a), (c)] and the four-cluster scenario [Fig. 1(b), (e)]. This initial influx of fish would probably have originated from refugia connected to the Illinois River and Fox River corridors that colonized Lake Chicago through the newly formed Chicago outlet (Dyke \& Prest, 1987).

A second colonization event [Fig. 1(b), (f)] in the central Muskegon and central Kalamazoo River basins is suggested by these results. This unique genetic signature may have originated from the admixture of $C$. bairdii already present in the basin from the initial colonization and the introduction of populations from refugia that experienced a later connection. Most notably, as ice retreated north of the Straits of Mackinac around 12000 B.P. (Dyke \& Prest, 1987), the hydrologic connection between ancestral lakes Michigan and Huron possibly allowed for colonization of the basin from eastern refugia. The ancestral Great Lakes water levels varied as the glacier retreated and re-advanced repeatedly until finally exiting the basin northward $c .9500$ B.P. At about the same time, the St Lawrence valley became ice free, creating a deep-drainage 
channel from North Bay in northern Lake Huron to the Atlantic Ocean. Consequently, water levels decreased dramatically to the Chippewa low level, $c .80 \mathrm{~m}$ lower than the contemporary Lake Michigan level and created a ridge across the central Lake Michigan basin [Fig. 1(g); Colman et al., 1994]. Following genetic divergence of C. bairdii caused by separation of the northern and southern Lake Chippewa basins, a third colonization event appears probable, which accounted for unique genetic signatures in the western part of the northern and southern [Fig. 1(b), (g)] river basins. While this final hypothesized vicariant event, which was caused by a reduction in the ancestral Lake Michigan water level, was not detected in the two-cluster scenario due to its inherently coarser scale, a secondary colonization event of the western populations was clearly consistent with the two-cluster scenario [Fig. 1(a), (c)]. Additionally, river capture, whereby a stream is diverted into the drainage of a neighbouring basin, cannot be excluded as a mechanism that contributed to the interpopulation structure observed across the study sites (Riffel \& Schreiber, 1995).

Behaviour of $C$. bairdii, and knowledge of geological processes that formed Great Lakes tributaries, add important context to the above-proposed hypothesis. For example, because $C$. bairdii experience strong density-dependent population dynamics (Grossman et al., 2006) and strong territoriality (Petty \& Grossman, 2004, 2007), it is probably difficult for invading populations to encroach on established populations, which could account for the relatively clear boundaries documented on an east-west gradient. Additionally, downstream reaches of rivers probably took longer to become hospitable to cool-water fishes such as cottids. For instance, during times of high water [e.g. Glenwood I and Glenwood II lake phases; Fig. 1(c), (e)] marshes that were present well inland of the modern Lake Michigan shoreline were probably too warm to support $C$. bairdii populations. Furthermore, the tributaries along these postglacial landscapes typically took millennia to form as natural springs slowly eroded sediments to connect wetlands to rivers, ultimately creating small coldwater streams where $C$. bairdii population now occur (Becker, 1983). Therefore, early in the postglacial history of the major rivers, headwater areas probably become habitable first, further supporting the hypothesis that the uppermost reaches were the earliest colonized. Similar colonization patterns that require traversing suboptimal cottid habitats (analogous to large historical Lake Michigan coastal wetlands) also have been suggested in European Cottus lineages (Kontula \& Väinölä, 2001; Hänfling et al., 2002). Additionally, recent research on $C$. bairdii recolonization following the restoration of stream-channel connectivity indicates that individuals are capable of relatively large movements into newly available habitat (up to $839 \mathrm{~m}$ over 1 year), facilitating rapid colonization in the absence of conspecifics (Deboer et al., 2015).

Results of the genetic analyses presented here are of taxonomic interest, as two morphologically similar $C$. bairdii subspecies have been identified within this study's geographic range. Robins (1954) detected both C. b. bairdii and C. b. kumlieni occurring in the eastern Lake Michigan basin with varying degrees of introgression between the taxa. Penoyer Creek, another tributary of the Muskegon River with its confluence located $c .4 \mathrm{~km}$ downstream of the Bigelow Creek confluence, was identified as a potential introgression site based on individuals from that site being morphology intermediate between the two subspecies (Robins, 1954). If the interpopulation structuring detected by this study is attributable to differences at the subspecies level, introgression between subspecies could have occurred in Bigelow Creek as it was identified in both the two and four-cluster scenarios as assigning to multiple clusters. Additionally, the 
Kalamazoo River may contain both subspecies with a smaller or absent introgression zone. Robins (1954) specifically notes that introgression appears to be more common in certain regions than others, which may be supported by the clear separation identified in the Kalamazoo River basin relative to the introgression zone evident in the Muskegon River basin. Conversely, the similarity between $c o I$ sequences presented here and its lack of congruence with microsatellite analyses (Fig. 2) do not support the divergence to the subspecies level for individuals included in this study. Additional research on the morphological differences paired with mtDNA sequencing of individuals from this region will be necessary to evaluate potential presence of $C$. $b$. bairdii and C.b. kumlieni subspecies.

Strong interpopulation genetic structure, generally sedentary behaviour that limits dispersal once populations are established and a lack of strong anthropogenic dispersal vectors (e.g. stocking) combine to make $C$. bairdii a model species for evaluating hypotheses of postglacial colonization of the Great Lakes basin. Moreover, clear differentiation among geographically proximal populations indicates that $C$. bairdii and other Cottus species provide an opportunity to study genetic structure at a higher resolution and smaller spatial scale than is typically possible with more mobile species that probably have greater gene flow among neighbouring populations and consequently less defined interpopulation structure (Kontula \& Väinölä, 2001; Vonlanthen et al., 2007; Lamphere \& Blum, 2012). If the methods presented here were applied to a larger geographic scale, then fine-scale delineations among regions recolonized from different glacial refugia and the formation of a recolonization chronology may be possible, which could improve the understanding of aquatic entryways into the Great Lakes basin following deglaciation. Finally, application of the methods described here to other native, small-bodied, non-game species (e.g. Etheostoma Rafinesque 1891, Percina Haldeman 1842 and Rhinichthys Agassiz 1849) throughout the Lake Michigan basin should be assessed in light of this study's proposed postglacial recolonization progression.

Laboratory technical support was provided by J. Newton, D. Wcisel and G. Chorak and field assistance was provided by B. Harris, S. Provo and J. Wesolek. M. T. Kinnison provided valuable comments on an earlier draft. J. Homola received financial support through a research assistantship from Annis Water Resources Institute and research funding from the Grand Valley State University Presidential Research Grant.

\section{Supporting Information}

Supporting Information may be found in the online version of this paper:

Appendix SI. Microsatellite and mitochondrial PCR conditions.

Appendix SII. Principal component analysis.

TABLE SI. Polymerase chain reaction conditions for six Cottus bairdii microsatellite loci.

TABLE SII. Mean values of five variables included in principal component analysis of environmental characteristics for 16 Michigan streams ( \pm S.D.).

FIG. S1. Maximum likelihood tree of cytochrome $c$ oxidase I (coI) mitochondrial DNA sequences for 160 Cottus bairdii sampled from 16 Lake Michigan tributaries and C. bairdii, C. cognatus, C. ricei, C. aleuticus and C. asper voucher specimen. Stream abbreviation codes are defined in Table II. 
FIG. S2. Relationships between genetic distance measures of $(a, b)$ chord distance and (c, d) $F_{\mathrm{ST}}\left(1-F_{\mathrm{ST}}\right)^{-1}$ and geographic distance measures of (a, c) direct (Euclidean) distance and (b, d) distance via waterways between sampling locations. (a) $y=0.003 x+0.299, r^{2}=0.07, P<0.05$; (b) $y=0.002 x+0.291, r^{2}=0.11, P<0.01$; (c) $y=0.001 x+0.227, r^{2}=0 \cdot 14, P<0 \cdot 01$; (d) $y=0.001 x+0 \cdot 200, r^{2}=0 \cdot 14, P<0 \cdot 01$.

FIG. S3. Evanno $\Delta K$ plots for Bayesian clustering analysis (a) with and (b) without using sampling location as a prior for mottled sculpin Cottus bairdii sampled from 16 eastern tributaries of Lake Michigan, U.S.A. $\Delta K=\left(\left|L^{\prime \prime} K\right|\right)[\text { s.D. }(L K)]^{-1}$.

FIG. S4. Bayesian clustering plots for $(\mathrm{a}, \mathrm{b})$ two-cluster $(K=2)$, and (c, d) four-cluster schemes $(K=4)$ and two analysis approaches: (a, c) without and (b, d) with location as a prior Cottus bairdii sampled from 16 eastern tributaries of Lake Michigan, U.S.A. Each individual is represented as a vertical column that is divided into $K$ coloured segments indicating cluster membership posterior probabilities. Vertical black lines separate sampling sites. See Table SII for names of sample sites in full.

Fig. S5. Neighbor-joining tree based on Cavalli-Sforza \& Edwards (1967) chord distances from six Cottus bairdii microsatellite loci sampled from 16 populations in western Michigan, U.S.A. with branching confidence measures based on 500 bootstrapped replicates. See main text Table II for sample site codes.

Fig. S6. Approximate locations of dams (-) for five western Michigan rivers and 16 smaller tributaries containing sampled Cottus bairdii populations. Data provided by U.S. Army Corps of Engineers National Inventory of Dams (http://nid.usace.army.mil/ cm_apex/f?p=838:1:0::NO::APP_ORGANIZATION_TYPE,P12_ORGANIZATION: 15/). See main text Table II for sample site codes.

\section{References}

April, J. \& Turgeon, J. (2006). Phylogeography of the banded killifish (Fundulus diaphanus): glacial races and secondary contact. Journal of Fish Biology 69, 212-228.

Avise, J. C., Arnold, J., Ball, R. M., Bermingham, E., Lamb, T., Neigel, L. E., Reeb, C. A. \& Saunders, N. C. (1987). Intraspecific phylogeography: the mitochondrial DNA bridge between population genetics and systematics. Annual Review of Ecology, Evolution, and Systematics 18, 489-522.

Bailey, R. M. \& Smith, G. R. (1981). Origin and geography of the fish fauna of the Laurentian Great Lakes basin. Canadian Journal of Fisheries and Aquatic Sciences 38, 1539-1561. doi: 10.1139/f81-206

Becker, G. C. (1983). Fishes of Wisconsin. Madison, WI: University of Wisconsin Press.

Bernatchez, L. \& Wilson, C. C. (1998). Comparative phylogeography of Nearctic and Palearctic fishes. Molecular Ecology 7, 431-452.

Breen, M. J., Ruetz, C. R., Thompson, K. J. \& Kohler, S. L. (2009). Movements of mottled sculpins (Cottus bairdii) in a Michigan stream: how restricted are they? Canadian Journal of Fisheries and Aquatic Sciences 66, 31-41. doi: 10.1139/F08-189

Brunner, P., Douglas, M. R. \& Bernatchez, L. (1998). Microsatellite and mitochondrial DNA assessment of population structure and stocking effects in arctic charr Salvelinus alpinus (Teleostei: Sal- monidae) from central alpine lakes. Molecular Ecology 7, 209-223.

Cavalli-Sforza, L. L. \& Edwards, A. W. (1967). Phylogenetic analysis models and estimation procedures. American Journal of Human Genetics 19, 233-257.

Colman, S. M., Forester, R. M., Reynolds, R. L., Sweetking, D. S., King, J. W., Gangemi, P., Jones, G. A., Keigwin, L. D. \& Foster, D. S. (1994). Lake-level history of Lake Michigan for the past 12000 years: the record from deep lacustrine sediments. Journal of Great Lakes Research 20, 73-92.

Deboer, J. A., Holtgren, J. M., Ogren, S. A. \& Snyder, E. B. (2015). Movement and habitat use by mottled sculpin after restoration of a sand-dominated $1^{\text {st }}$ order stream. American Midland Naturalist 173, 335-345. doi: 10.1674/amid-173-02-335-345.1 
Dieringer, D. \& Schlötterer, C. (2003). Microsatellite analyser (MSA): a platform independent analysis tool for large microsatellite data sets. Molecular Ecology Notes 3, 167-169. doi: 10.1046/j.147-8286.2003.00351.x

Dyke, A. S. \& Prest, V. K. (1987). Late Wisconsinan and Holocene history of the Laurentide ice sheet. Géographie Physique et Quaternaire 41, 237-263.

Earl, D. A. \& vonHoldt, B. M. (2012). STRUCTURE HARVESTER: a website and program for visualizing STRUCTURE output and implementing the Evanno method. Conservation Genetics Resources 4, 359-361. doi: 10.1007/s12686-011-9548-7

Englbrecht, C. C., Largiadér, C. R., Hänfling, B. \& Tautz, D. (1999). Isolation and characterization of polymorphic microsatellite loci in the European bullhead Cottus gobio L. (Osteichthyes) and their applicability to related taxa. Molecular Ecology 8, 1957-1969. doi: 10.1046/j.1365-294x.1999.00778-6.x

Englbrecht, C. C., Freyhof, J., Nolte, A., Rassmann, K., Schliewen, U. \& Tautz, D. (2000). Phylogeography of the bullhead Cottus gobio (Pisces: Teleostei: Cottidae) suggests a pre-Pleistocene origin of the major central European populations. Molecular Ecology 9, 709-722.

Evanno, G., Regnaut, S. \& Goudet, J. (2005). Detecting the number of clusters of individuals using the software STRUCTURE: a simulation study. Molecular Ecology 14, 2611-2620. doi: 10.1111/j.1365-294X.2005.02553.x

Excoffier, L. \& Lischer, H. E. L. (2010). Arlequin suite ver 3.5: a new series of programs to perform population genetics analyses under Linux and Windows. Molecular Ecology Resources 10, 564-567. doi: 10.1111/j.1755-0998.2010.02847.x

Faber, J. E., Rybka, J. \& White, M. M. (2009). Intraspecific phylogeography of the stonecat madtom, Noturus flavus. Copeia 2009, 563-571.

Falush, D., Stephens, M. \& Pritchard, J. K. (2003). Inference of population structure using multilocus genotype data: linked loci and correlated allele frequencies. Genetics 164, $1567-1587$.

Falush, D., Stephens, M. \& Pritchard, J. K. (2007). Inference of population structure using multilocus genotype data: dominant markers and null alleles. Molecular Ecology Notes 7, 574-578. doi: 10.1111/j.1471-8286.2007.01758.x

Fiumera, A. C., Porter, B. A., Grossman, G. D. \& Avise, J. C. (2002). Intensive genetic assessment of the mating system and reproductive success in a semi-closed population of the mottled sculpin, Cottus bairdii. Molecular Ecology 11, 2367-2377. doi: 10.1046/j.1365-294X.2002.01585.x

Fujishin, L. M., Barker, F. K., Huff, D. D. \& Miller, L. M. (2009). Isolation of 13 polymorphic microsatellite loci for slimy sculpin (Cottus cognatus). Conservation Genetics Resources 1, 429-432. doi: 10.1007/s12686-009-9099-3

Grossman, G. D., Ratajczak, R. E., Petty, J. T., Hunter, M. D., Peterson, J. T. \& Grenouillet, G. (2006). Population dynamics of mottled sculpin (Pisces) in a variable environment: information theoretic approaches. Ecological Monographs 76, 217-234.

Hänfling, B., Hellemans, B., Volckaert, F. A. M. \& Carvalho, G. R. (2002). Late glacial history of the cold-adapted freshwater Cottus gobio, revealed by microsatellites. Molecular Ecology 11, 1717-1729.

Hewitt, G. M. (1996). Some genetic consequences of ice ages and their role in divergence and speciation. Biological Journal of the Linnean Society 58, 247-276.

Hickerson, M. J., Carstens, B. C., Cavender-Bares, J., Crandall, K. A., Graham, C. H., Johnson, J. B., Rissler, L., Victoriano, P. F. \& Yoder, A. D. (2010). Phylogeography's past, present and future: 10 years after Avise, 2000. Molecular Phylogenetics and Evolution 54, 291 -301. doi: 10.1016/j.ympev.2009.09.016

Homola, J. J., Ruetz, C. R., Kohler, S. L. \& Thum, R. A. (2014). Weak effects of a microsporidian parasite on mottled sculpin in Michigan streams. Canadian Journal of Fisheries and Aquatic Sciences 71, 915-926.

Hubbs, C. L., Lagler, K. F. \& Smith, G. R. (2004). Fishes of the Great Lakes Region. Ann Arbor, MI: University of Michigan Press.

Hubert, N., Hanner, R., Holm, E., Mandrak, N. E., Taylor, E., Burridge, M., Watkinson, D., Dumont, P., Curry, A., Bentzen, P., Zhang, J., April, J. \& Bernatchez, L. (2008). Identifying Canadian freshwater fishes through DNA barcoding. PLoS One 3, e2490. doi: 10.1371/journal.pone.0002490 
Hubisz, M. J., Falush, D., Stephens, M. \& Pritchard, J. K. (2009). Inferring weak population structure with the assistance of sample group information. Molecular Ecology Resources 9, 1322-1332. doi: 10.1111/j.1755-0998.2009.02591.x

Jakobsson, M. \& Rosenberg, N. A. (2007). CLUMPP: a cluster matching and permutation program for dealing with label switching and multimodality in analysis of population structure. Bioinformatics 23, 1801-1806. doi: 10.1093/bioinformatics/btm233

Jombart, T. (2008). adegenet: a R package for the multivariate analysis of genetic markers. Bioinformatics 24, 1403-1405. doi: 10.1093/bioinformatics/btn129

Jombart, T., Devillard, S. \& Balloux, F. (2010). Discriminant analysis of principal components: a new method for the analysis of genetically structured populations. BMC Genetics 11, 94. doi: 10.1186/1471-2156-11-94

Klicka, J. \& Zink, R. M. (1997). The importance of recent ice ages in speciation: a failed paradigm. Science 277, 1666-1669. doi: 10.1126/science.277.5332.1666

Kontula, T. \& Väinölä, R. (2001). Postglacial colonization of Northern Europe by distinct phylogeographic lineages of the bullhead, Cottus gobio. Molecular Ecology 10, 1983-2002.

Lamphere, B. A. \& Blum, M. J. (2012). Genetic estimates of population structure and dispersal in a benthic stream fish. Ecology of Freshwater Fish 21, 75-86. doi: 10.1111/j.1600-0633.2011.00525.x

Manel, S., Schwartz, M., Luikart, G. \& Taberlet, P. (2003). Landscape genetics: combining landscape ecology and population genetics. Trends in Ecology and Evolution 18, 189-197.

Manni, F., Guerard, E. \& Heyer, E. (2004). Geographic patterns of (genetic, morphologic, linguistic) variation: how barriers can be detected by using Monmonier's algorithm. Human Biology 76, 173-190.

Marske, K. A., Rahbek, C. \& Nogues-Bravo, D. (2013). Phylogeography: spanning the ecology-evolution continuum. Ecography 36, 1169-1181. doi: 10.1111/j.1600-0587. 2013.00244.x

Monmonier, M. S. (1973). Maximum-difference barriers: an alternative numerical regionalization method. Geographical Analysis 3, 245-261.

Murdoch, M. H. \& Hebert, P. D. N. (1997). Mitochondrial DNA evidence of distinct glacial refugia for brown bullhead (Ameiurus nebulosus) in the Great Lakes. Canadian Journal of Fisheries and Aquatic Sciences 54, 1450-1460.

Nolte, A. W., Stemshorn, K. C. \& Tautz, D. (2005). Direct cloning of microsatellite loci from Cottus gobio through a simplified enrichment procedure. Molecular Ecology Notes 5, 628-636. doi: 10.1111/j.1471-8286.2005.01026.x

van Oosterhout, C., Hutchinson, W. F., Wills, D. P. M. \& Shipley, P. (2004). Micro-checker: software for identifying and correcting genotyping errors in microsatellite data. Molecular Ecology Notes 4, 535-538.

Petty, J. T. \& Grossman, G. D. (2004). Restricted movement by mottled sculpin (Pisces: Cottidae) in a southern Appalachian stream. Freshwater Biology 49, 631-645. doi: 10.1111/j.1365-2427.2004.01216.x

Petty, J. T. \& Grossman, G. D. (2007). Size-dependent territoriality of mottled sculpin in a southern Appalachian stream. Transactions of the American Fisheries Society 136, 1750-1761. doi: 10.1577/T06-034.1

Piller, K. R., Bart, H. L. Jr. \& Hurley, D. L. (2008). Phylogeography of the greenside darter complex, Etheostoma blennioides (Teleostomi: Percidae): a wide-ranging polytypic taxon. Molecular Phylogenetics and Evolution 46, 974-985.

Pringle, C. M., Freeman, M. C. \& Freeman, B. J. (2000). Regional effects of hydrological alterations on riverine macrobiota in the New World: tropical-temperate comparisons. BioScience 50, 807-823.

Pritchard, J. K., Stephens, M. \& Donnelly, P. (2000). Inference of population structure using multilocus genotype data. Genetics 155, 945-959.

Ray, J. M., Wood, R. M. \& Simons, A. M. (2006). Phylogeography and postglacial colonization patterns of the rainbow darter, Etheostoma caeruleum (Teleostei: Percidae). Journal of Biogeography 33, 1550-1558.

Rice, W. R. (1989). Analyzing tables of statistical tests. Evolution 43, 223-225.

Riffel, M. \& Schreiber, A. (1995). Coarse-grained population-structure in central European sculpin (Cottus gobio L) - secondary contact or ongoing genetic drift? Journal of Zoological Systematics and Evolutionary Research 33, 173-184. 
Robins, C. R. (1954). A taxonomic revision of the Cottus bairdii and Cottus carolinae species groups in eastern North America (Pisces, Cottidae). PhD Thesis, Cornell University, Ithaca, NY, U.S.A.

Rosenberg, N. (2004). DISTRUCT: a program for the graphical display of population structure. Molecular Ecology Notes 4, 137-138. doi: 10.1046/j.1471-8286.2003.00566.x

Rousset, F. (2008). Genepop'007: a complete reimplementation of the Genepop software for Windows and Linux. Molecular Ecology Resources 8, 103-106.

Shafer, A. B., Cullingham, C. I., Cote, S. D. \& Coltman, D. W. (2010). Of glaciers and refugia: a decade of study sheds new light on the phylogeography of northwestern North America. Molecular Ecology 19, 4589-4621. doi: 10.1111/j.1365-294X.2010.04828.x

Slatkin, M. (1993). Isolation by distance in equilibrium and non-equilibrium populations. Evolution 47, 264-279.

Stepien, C. A. \& Faber, J. E. (1998). Population genetic structure, phylogeography and spawning philopatry in walleye (Stizostedion vitreum) from mitochondrial DNA control region sequences. Molecular Ecology 7, 1757-1769.

Tamura, K., Stecher, G., Peterson, D., Filipski, A. \& Kumar, S. (2013). MEGA6: molecular evolutionary genetics analysis version 6.0. Molecular Biology and Evolution 30, 2725-2729.

Vonlanthen, P., Excoffier, L., Bittner, D., Persat, H., Neuenschwander, S. \& Largiader, C. R. (2007). Genetic analysis of potential postglacial watershed crossings in Central Europe by the bullhead (Cottus gobio L.) Molecular Ecology 16, 4572-4584. doi: 10.1111/j.1365-294X.2007.03531.x

Weir, B. \& Cockerham, C. (1984). Estimating $F$-statistics for the analysis of population structure. Evolution 38, 1358-1370.

Wright, S. (1943). Isolation by distance. Genetics 31, 39-59.

Yokoyama, R. \& Goto, A. (2005). Evolutionary history of freshwater sculpins, genus Cottus (Teleostei; Cottidae) and related taxa, as inferred from mitochondrial DNA phylogeny. Molecular Phylogenetics and Evolution 36, 654-668.

Young, M. K., Mckelvey, K. S., Pilgrim, K. L. \& Schwartz, M. K. (2013). DNA barcoding at riverscape scales: assessing biodiversity among fishes of the genus Cottus (Teleostei) in northern Rocky Mountain streams. Molecular Ecology Resources 13, 583-595.

\section{Electronic References}

ESRI (2011). ArcGIS Desktop: Release 10. Redlands, CA: Environmental Systems Research Institute. Available at http://www.esri.com/software/arcgis/arcgis-for-desktop/

Felsenstein, J. (2005). PHYLIP (Phylogeny Inference Package) Version 3.6. Washington, WA: University of Washington, Seattle. Available at http://evolution.genetics.washington.edu/ phylip.html/

Goudet, J. (2001). FSTAT, a Program to Estimate and Test Gene Diversities and Fixation Indices (Version 2.9.3). Lausanne: Institut d'Écologie, Université de Lausanne. Available at http://www2.unil.ch/popgen/softwares/fstat.htm/

Oksanen, J., Blanchet, F. G., Kindt, R., Legendre, P., Minchin, P. R., O’Hara, R. B., Simpson, G. L., Solymos, P., Stevens, H. H. \& Wagner, H. (2012). vegan: Community Ecology Package. $R$ Package Version 2.0-5. Available at http://CRAN.R-project.org/package=vegan/ 